\title{
Comparison of surgeon-performed ultrasound-guided fine needle aspiration cytology with histopathological diagnosis of thyroid nodules
}

\author{
Muhammad Ayoob Jat
}

\begin{abstract}
Objective: To assess the Solitary thyroid nodules by surgeon-performed ultrasound-guided FNAC and evaluate with the histopathological findings.

Methods: This study includes 100 Consecutive patients of a solitary thyroid nodule which were presented to the Outpatients Department of Surgery during the period of two years from September 2016 to August 2018. Exclusion criteria were patients with extra-thyroid swelling, diffuse goiter and multinodular goiter. All patients with a solitary thyroid nodule underwent Surgeon -performed ultrasound-guided FNAC in the department of Radiology. After thyroid surgery, thyroid specimens were sent for histopathology and evaluate with FNAC findings.

Results: The study included hundred patients with solitary thyroid nodule, 75(75\%) female and 25 (25\%) male with a ratio of $F 3: 1 \mathrm{M}$. The age of the patients ranged from 15-75 years with a mean age of 35 years. The result of 100 cases of Surgeon -performed Ultrasound -guide FNAC of a solitary thyroid nodule were inconclusive in 10 cases (10\%), Non-neoplastic in 60 cases $(60 \%)$ and Neoplastic lesions in 30 cases (30\%). After evaluation of findings from FNAC and histopathology, four cases with benign FNAC (adenomatous/colloid Goiter) turnout as neoplastic (papillary carcinoma) on histopathology and six cases with neoplastic FNAC (papillary carcinoma), just two cases turnout as benign (nodular colloid goiter with cystic degeneration) on histopathology. In present study Surgeon - performed Us FNAC has found to be $87.5 \%$ sensitive, $95.3 \%$ specific and $92.0 \%$ diagnostic accuracy.

Conclusion: Surgeon - performed Ultrasound-guided FNAC is a safe, simple and accurate technique in the diagnosis of solitary thyroid nodule.
\end{abstract}

KEYWORDS: Fine needle aspiration cytology, Histopathology, Solitary thyroid nodule.

doi: https://doi.org/10.12669/pjms.35.4.537

How to cite this:

Jat MA. Comparison of surgeon-performed ultrasound-guided fine needle aspiration cytology with histopathological diagnosis of thyroid nodules. Pak J Med Sci. 2019;35(4):1003-1007. doi: https://doi.org/10.12669/pjms.35.4.537

This is an Open Access article distributed under the terms of the Creative Commons Attribution License (http://creativecommons.org/licenses/by/3.0), which permits unrestricted use, distribution, and reproduction in any medium, provided the original work is properly cited.

1. Dr. Muhammad Ayoob Jat, Assistant Professor Surgery,

Department of Surgery, College of Medicine, Northern Border University, Arar, KSA.

Correspondence:

Dr. Muhammad Ayoob Jat,

Postal Address: Dr. Muhammad Ayoob Jat, High Life Corner,

$1^{\text {st }}$ Floor Flat No.: 345-A/1,

Teek Chand Street Near Shamshi Masjid,

Sukkur, Sindh, Pakistan.

Email: dr.ayubjat@yahoo.com

* Received for Publication:

* Revision Received:

* Revision Accepted:
February 7, 2019

May 7, 2019

May 15, 2019

\section{INTRODUCTION}

Solitary thyroid nodule is a common surgical problem presents in surgical clinic at outpatients department. Solitary thyroid nodule is defined clinically as a palpably discrete swelling within an otherwise apparently normal gland, is usually a benign lesion. A different diagnostic tools like ultrasound, thyroid nuclear scan, and fine needle aspiration cytology (FNAC) are available to the clinician for evaluation of thyroid nodule but FNAC is considered the gold standard diagnostic tool in the evaluation of a thyroid nodule, The prevalence 
of thyroid nodules has been estimated to be as high as $64 \%$, with the incidence of malignancy ranging from 5 to $10 \%$, depending on the population under study. ${ }^{1}$

Fine needle aspiration cytology (FNAC) is a rapid, minimally invasive, and cost-effective first-line an invaluable tool for Us-FNAC the establishing the diagnosis of thyroid nodules. ${ }^{2}$ Ultrasound-guided FNAC has a higher diagnostic accuracy than conventional (palpation-guided) FNAC. ${ }^{3}$ In current clinical practice, it is important for a surgeon to be capable of performing Us-FNAC for a broad range of head and neck sites including the thyroid, salivary glands, and lymph nodes. However, most studies of surgeon-performed USFNAC have focused on thyroid nodules. ${ }^{4}$ On review of literature there is evidence that ultrasound -guided surgeon-performed FNAC carries a number of benefits, including reduction of multiple physician visits, assessment by a physician familiar with neck anatomy, as well as potentially decreasing wait times to surgery. ${ }^{5}$

The purpose of this study was to evaluate the Solitary thyroid nodules by surgeon-performed ultrasound-guided FNAC and compare with the histopathological diagnosis. Also to determine the sensitivity, specificity and accuracy of Surgeonperformed Ultrasound-guided FNAC.

\section{METHODS}

This cross-sectional prospective study was conducted for the period of two years from Sept 2016- August 2018 in the Department of surgery, at central hospital, Arar, KSA. During this study period we accepted all patients came in OPD with clinically diagnosed as a solitary thyroid nodule having no hyper or hypothyroidism, irrespective of age and sex (inclusion criteria). Exclusion criteria were patients presenting with extra-thyroid neck swelling. This study is not applicable in patients having toxic or non- toxic diffuse or multinodular goiter. A total of 100 patients with solitary thyroid nodule were presented in Surgical Clinic during study period. A detailed Clinical history and thorough physical examination was carried out and recorded on clinical proforma. Routine blood chemistry, Ultrasonography of Neck, thyroid function tests in all cases but radioiodine scan, computed tomography in selected cases. A wellinformed consent was taken from all patients. The technique, risks, benefits, and associated complications of the procedure were explained to all patients.
Ultrasound-guided FNAC was performed by surgeon in all cases of solitary thyroid nodule in the Department of Radiology. The patient was placed in a supine position with the neck extended and the right-handed surgeon at the right side of the patient. A G.E. LOGIC - E9 Ultrasound system with a high-frequency linear 6-15 MHz transducer was used. The Us-FNAC procedure was performed using a non-aspiration capillary technique with two passes of a 1.5-inch 21-gauge needle. The specimen was deposited onto a glass slide and smeared with another slide. The sample was immediately fixed to avoid desiccation artifacts. The collected material is placed on four glass slides, smeared, and fixed in 95\% ethyl alcohol for about 30 minutes. All the slides were stained with Papanicolaou stain. Specimens were reviewed for cellular adequacy onsite by the cytopathologist at the time of the procedure. The smear was considered adequate if there were at least five groups of well-visualized follicular cells, each group containing ten or more cells. In this study no complications associated with US-FNAC were reported.

About 75 patients subsequently underwent thyroid surgery and thyroid specimens were sent for histopathology then finally FNAC findings were compared with the histological findings to assess the sensitivity, specificity, positive predictive value, negative predictive value and overall diagnostic accuracy of Surgeon-performed Ultrasound guided Fine needle aspiration cytology.

\section{RESULTS}

A total of 100 patients with solitary thyroid nodule were presented in Surgical Clinic 75(75\%) female and $25(25 \%)$ male with a ratio of F 3:1M during study period. The age of the patients ranged from 15-75 years with a mean age of 35 years. The FNAC findings in this series for distribution of solitary thyroid lesion were: inconclusive FNAC in 10 cases $(10 \%)$, Non-neoplastic in 60 cases $(60 \%)$ and Neoplastic in 30 cases $(30 \%)$. As shown in Table-I.

In this study 75 cases were operated for thyroid surgery so their histopathological specimen available for comparison between FNAC and histopathological findings. Out of 45 non neoplastic lesions on FNAC, four lesions were turnout as neoplastic lesion on histopathology so accuracy of FNAC diagnosis was $91.1 \%$, while in neoplastic group, out of 30 patients, two cases was turnout as Non neoplastic lesion on histopathology so the accuracy rate was $93.3 \%$ as showed in Table-II. 
Table-I: Distribution of FNAC Findings in the Solitary Thyroid Nodules $(n=100)$.

\begin{tabular}{|c|c|c|c|}
\hline & Type of lesion & No & $\%$ \\
\hline Non-diagnostic / Inconclusive & & 10 & $10 \%$ \\
\hline \multirow[t]{6}{*}{ Non- neoplastic } & & 60 & \\
\hline & Hyperplastic nodule & 12 & $20 \%$ \\
\hline & Adenomatous goiter & 25 & $41.6 \%$ \\
\hline & Hemorrhagic colloid nodule & 15 & $25 \%$ \\
\hline & Hashimoto thyroiditis & 5 & $8.3 \%$ \\
\hline & Colloid cyst & 3 & $5 \%$ \\
\hline \multirow[t]{4}{*}{ Neoplastic } & & 30 & \\
\hline & Follicular Neoplastic & 22 & $73.4 \%$ \\
\hline & Hurthle cell adenoma & 2 & $6.6 \%$ \\
\hline & Papillary Carcinoma & 6 & $20 \%$ \\
\hline
\end{tabular}

Table-II: Cytohistopathological correlation of thyroid lesions $(\mathrm{n}=75)$.

\begin{tabular}{|c|c|c|c|c|c|c|}
\hline $\begin{array}{l}\text { S. } \\
\text { No. }\end{array}$ & FNAC Diagnosis & $N o=100$ & $\begin{array}{c}\text { Thyroid } \\
\text { Specimens } N=75\end{array}$ & Match & $\begin{array}{l}\text { Mismatch } \\
\text { diagnosis }\end{array}$ & Histopathological \\
\hline 1 & Non-diagnostic / Inconclusive & 10 & - & - & - & NA \\
\hline 2 & Adenomatous / colloid Goiter & 40 & 40 & 36 & 4 & $\begin{array}{l}36 \text { Colloid Goiter } \\
4 \text { Cystic Papillary carcinoma }\end{array}$ \\
\hline 3 & Hyperplastic nodules & 12 & -- & -- & -- & NA \\
\hline 4 & Hashimoto thyroiditis & 5 & 5 & 5 & --- & 5 Hashimoto thyroiditis \\
\hline 5 & Colloid cyst & 3 & -- & -- & --- & NA \\
\hline 6 & Hurthle cell neoplasm & 2 & 2 & 2 & --- & 2 Hurthle cell adenoma \\
\hline 8 & Follicular Neoplasm & 22 & 22 & 22 & & $\begin{array}{l}20 \text { Follicular adenoma } \\
2 \text { Follicular carcinoma }\end{array}$ \\
\hline 9 & Malignant Papillary carcinoma & 6 & 6 & 4 & 2 & $\begin{array}{l}4 \text { Papillary carcinoma } \\
2 \text { Nodular colloid goiter } \\
\text { with cystic degeneration }\end{array}$ \\
\hline & Total & 100 & 75 & 69 & 06 & \\
\hline
\end{tabular}

Abbreviations: FN: False negative; FP: False positive, TN: True negative, TP: True positive.

Statistical Analysis of Thyroid Nodules: Statistical analysis was done using MS Excel 2010. In this study the sensitivity, specificity, positive predictive value, negative predictive value and overall diagnostic accuracy of Fine needle aspiration cytology were calculated by correlating the results of cytology with histopathology by using Galen and Gambino method with following formulas. Table-III.

1. Sensitivity $=\mathrm{TP} / \mathrm{TP}+\mathrm{FN} \times 100$---------- $=$ $87.5 \%$

2. Specificity $=\mathrm{TN} / \mathrm{TN}+\mathrm{FP} \times 100$
95.3\%

3. Positive predictive value $=\mathrm{TP} / \mathrm{TP}+\mathrm{FP} \times 100--$ $=93.3 \%$

4. Negative predictive value $=\mathrm{TN} / \mathrm{TN}+\mathrm{FN} \times 100$ $=91.1 \%$

5. Accuracy $=\mathrm{TP}+\mathrm{TN} / \mathrm{TP}+\mathrm{TN}+\mathrm{FP}+\mathrm{FN} \times 100=$ $92.1 \%$

\section{DISCUSSION}

Surgeon-performed Ultrasound-guided FNAC has gained popularity in the recent literature, as a method to further decrease surgical waittime as well as increase patient convenience and

Table-III: Analysis of FNAC and Histopthological diagnosis of Solitary thyroid nodules (n=75).

\begin{tabular}{llcccc}
\hline & & Histopatho & Logy & Total & Discordant cases \\
\hline \multirow{2}{*}{ CYTOLOGY } & Benign & Benign & Malignant & & \\
& Malignant & $41(\mathrm{TN})$ & $4(\mathrm{FN})$ & 45 & $4(\mathrm{FN})$ \\
& $2(\mathrm{FP})$ & $28(\mathrm{TP})$ & 30 & $2(\mathrm{FP})$ \\
\hline TOTAL & 43 & 32 & 75 & \\
\hline
\end{tabular}


satisfaction due to a decreased number of specialist referrals $s^{6,7}$ Ultrasound- guided FNAC improves the cytological diagnostic accuracy, compared to palpation-guided FNAC. ${ }^{8}$ In present study the accuracy of Surgeon -performed -Us-FNAC is $92 \%$ but in some studies accuracy up to $97 \%$ in the preoperative diagnosis of various thyroid lesions. ${ }^{9,10}$ The adequacy rate of FNAC is dependent on the availability of a cytopathologist for immediate specimen assessment. ${ }^{11,12}$ Surgeon-performed ultrasound (SPUs) has become an extension of the physical examination in the evaluation of patients with thyroid nodules. ${ }^{13}$ In general, histological examination must be done to distinguish between follicular carcinoma and benign follicular adenoma as invasion through the tumor capsule or vascular invasion is evidence of carcinoma. International guidelines recommend that repeat aspiration under Ultrasound-guidance to augment the accuracy in $15-25 \%$ of thyroid nodules in which FNA yields inadequate diagnostic material. ${ }^{14}$

This study includes hundred patients with solitary thyroid nodule, $75(75 \%)$ female and 25 (25\%) male with a ratio of F 3:1M. The age of patient ranged from 15-75 years with a mean age of 34 years .In study by Dr. Shemy et al. ${ }^{15}$ out of 50 cases of thyroid nodules 41 were female and 9 were male with a ratio of (F: $M-5: 1)$, common in the age group of 30- 39 years. The findings of Surgeon-performed Us- FNAC of solitary thyroid nodule shows 10 cases $(10 \%)$ were inconclusive/ Non-diagnostic, 60 cases (60\%) Non-neoplastic (40 adenomatous/colloid goiters, 12 hyperplastic nodules, five Hashimoto thyroiditis, three colloid cyst) and 30 cases (30\%) Neoplastic lesions (follicular neoplasm 22(73.4\%), Hurthle cell adenoma $2(6.6 \%)$, papillary carcinoma $6(20.0 \%)$.This study shows that non-diagnostic rate of Usg-FNAC was 10\% (10/100) similar result seen in study by Oktay I et al 10\% (47 of 470), ${ }^{16}$ but $5.6 \%$ in study by Bohacek L et al. ${ }^{17} \mathrm{~A}$ major factor associated with inadequate US-FNAC results is cystic changes within the tumor and another factor is presence of rim calcification. ${ }^{18,19}$ All 10 patients with inconclusive FNAC reports $(10 \%)$ underwent repeat FNAC, which was turnout as benign in 8 cases $(80 \%)$ and non-diagnostic in two cases. All these Patients were followed with serial Ultrasound and remain stable.

The present study shows 45 cases with benign FNAC, concordance in 41 cases (True Negative) and discordance in four cases (False Negative) turnout as papillary carcinoma and 30 case with malignant FNAC, concordance in 28 cases (True
Positive) two cases turnout as nodular colloid goiter with cystic degeneration (False positive). The fine needle cytology aspiration in four cases (False negative) diagnosed as nodular goiter with cystic degeneration consisted of straw colored fluid with foamy macrophages and abundant colloid were subsequently confirmed on histopathology as papillary carcinoma. Cystic papillary carcinoma is the commonest cause of false negative reports 17 . In this series six cases of papillary carcinoma on cytology, four were confirmed on histopathology, remaining two were nodular colloid goiter with cystic degeneration. Hence diagnostic accuracy of fine needle aspiration for papillary carcinoma was $66.6 \%$.

This study shows that the sensitivity, specificity and diagnostic accuracy of Surgeon -performed Ultrasound -guided FNAC for solitary thyroid nodules were $87.5 \%, 95.3 \%$, and $92.0 \%$ respectively. In study by Dr. Yagesh P et al., ${ }^{20}$ the sensitivity is $70 \%$ specificity is $94.7 \%$ and diagnostic accuracy is $86.2 \%$. In same study Out of total 90 cases of thyroid nodules FNAC Only 29 cases was operated and available for correlation with histological findings, in which 21 were diagnosed as benign and 8 as malignant on cytology, whereas 19 cases were diagnosed as benign and 10 as malignant on histopathology. There were 3 (false negative) and 1 (false positive) cases. In various studies by Amatya B et al., ${ }^{21}$ Rathod GB et al. ${ }^{22}$ and Musani MA et al., ${ }^{23}$ found incidence of false negative cases $5.4 \%, 13.6 \%$ and $4.7 \%$ respectively. False negative diagnosis in the cases with follicular patterns is one of the major FNAC limitations. FNAC cannot distinguish Carcinoma and follicular neoplasms thus excision is must for an accurate and definite diagnosis.

\section{CONCLUSION}

Surgeon - performed US-guided FNAC is a safe, simple and accurate technique in the diagnosis of solitary thyroid nodule. A team work between Surgeon, cytopathologist, and radiologist maximizes the diagnostic accuracy of FNAC. Repeated Ultrasound- guided FNAC has high diagnostic value in thyroid nodule where FNAC was insufficient or inconclusive.

Disclaimer: None.

Conflict of Interest: None.

Funding Sources: Deanship of scientific Research, Northern border University, ARAR, KSA. 


\section{REFERENCES}

1. Ogilvie JB, Piatigorsky EJ, Clark OH. Current status of fine needle aspiration for thyroid nodules. Adv Surg. 2006;40:223-238.

2. Robitschek J, Straub M, Wirtz E, Klem C, Sniezek J. Diagnostic efficacy of surgeon-performed ultrasoundguided fine-needle aspiration: A randomized controlled trial. Otolaryngol Head Neck Surg. 2010;142:306-309. doi: 10.1016/j.otohns.2009.11.011.

3. Iannuccilli JD, Cronan JJ, Monchik JM. Risk for malignancy of thyroid nodule as assessed by sonographic criteria: the need for biopsy. J Ultrasound Med. 2004;23(11):1455-1464.

4. Karadeniz CG, Emre AU, Tascilar O, Gultekin FA, Ozdamar $\mathrm{SO}$, Comert M. Diagnostic adequacy of surgeon-performed ultrasound-guided fine-needle aspiration biopsy of thyroid nodules. J Surg Oncol. 2013;107:206-210. doi: 10.1002/ jso. 23212

5. Seiberling KA, Dutra JC, Gunn J. Ultrasound-guided fine needle aspiration biopsy of thyroid nodules performed in the office. Laryngoscope. 2008;118:228-231. doi: 10.1097/MLG.0b013e318157465d.

6. Al-azawi D, Mann GB, Judson RT, Miller JA. Endocrine surgeon-performed US-guided thyroid FNAC is accurate and efficient. World J Surg. 2012;36:1947-1952. doi: $10.1007 /$ s00268-012-1592-2.

7. Karadeniz CG, Emre AU, Tascilar O, Gultekin FA, Ozdamar $\mathrm{SO}$, Comert M. Diagnostic adequacy of surgeon-performed ultrasound-guided fine needle aspiration biopsy of thyroid nodules. J Surg Oncol. 2013;107:206-210. doi: 10.1002/ jso.23212.

8. Izquierdo $\mathrm{R}$, Arekat $\mathrm{MR}$, Knudson PE, Kartun $\mathrm{KF}$, Khurana K, Kort K, et al. Comparison of palpationguided versus ultrasound-guided fine-needle aspiration biopsies of thyroid nodules in an outpatient endocrinology practice. Endocr Pract. 2006;12(6):609-614. doi: 10.4158/EP.12.6.609.

9. Gunvanti BR, Sangita R, Pragnesh P, Ashish P. Diagnostic efficacy of fine needle aspiration cytology in cervical lymphadenopathy-A one year study. IJMPS. 2014;4(5):01-08.

10. Rathod GB, Ghadiya V, Shinde P, Tandan RK. Pleomorphic sarcoma in 60 years old male-A case report. IJCMS. 2014;3(8):510-517.

11. Khanlari M, Daneshbod Y, Shaterzadeh HY, Shirian S, Negahban S, Aledavood A, et al. Discrepancy of target sites between clinician and cytopathological reports in head neck fine needle aspiration: Did I miss the target or did the clinician mistake the organ site? Cancer Med. 2015;4(9):1374 1380. doi: $10.1002 /$ cam 4.489 .
12. Khanlari M, Daneshbod $Y$, Shaterzadeh HY, Negahban $S$, Aledavood A, Oryan A, et al. Labeling errors in fine needle aspiration cytology. Cytopathology. 2015;27(4):297-299. doi: $10.1111 /$ cyt.12264.

13. Goldfarb M, Gondek S, Solorzano C, Lew JI. Surgeonperformed ultrasound can predict benignity in thyroid nodules. Surgery. 2011;150:436-441. doi: 10.1016/j. surg.2011.07.002.

14. Cramer H. Fine-needle aspiration cytology of the thyroid: an appraisal. Cancer Cytopathol. 2001;90(6):325-329. 10.1002/1097-0142(20001225)90:6<325.

15. Dr. Shemy. FNAC and Histopathological Correlation of Thyroid Lesions. GJRA. 2015;4(12):290-292.

16. Oktay I, Reyhan E, Kamuran CD, Demirturk P, Hasan E, Filiz EH, et al. Surgeon-Performed Ultrasound-Guided Thyroid Fine-Needle Aspiration Biopsy: Evaluation of 470 Biopsies. Hellenic J Surg. 2013;85:6:380-385. doi: 10.1007/ s13126-013-0070-0.

17. Bohacek L, Milas M, Mitchell J, Siperstein A, Berber E. Diagnostic Accuracy of Surgeon-Performed Ultrasound-Guided Fine-Needle Aspiration of Thyroid Nodules. Ann Surg Oncol. 2012;19:45-51. doi: 10.1245/ s10434-011-1807-z.

18. Garcia-Pascual L, Barahona MJ, Balsells $M$, Pozo CD, Anglada-Barcelo J, Casalots-Casado J. Complex thyroid nodules with nondiagnostic fine-needle aspiration cytology: histopathologic outcomes and comparison of the cytologic variants (cystic vs. acellular). Endocrine. 2011;39:33-40. doi: 10.1007/s12020-010-9409-2.

19. Grani G, Calvanese A, Carbotta G. Intrinsic factors affecting adequacy of thyroid nodule fine-needle aspiration cytology. Clin Endocrinol Oxford. 2013;78:141-144. doi: 10.1111/j.1365-2265.2012.04507.x.

20. Pawde Y, Rai R. Role of Fnac in Thyroid Lesions. Glob J Res Anal. 2016;5(3):439-442.

21. Amatya BB, Joshi AR, Singh SK. A study of fine needle aspiration cytology of head and neck masses and their corroboration by histopathology. Postgrad Med J. 2009;6(2):52-60.

22. Rathod GB, Parmar P. Fine needle aspiration cytology (FNAC) of swellings of head and neck region. Indian J Med Sci. 2012;66(3-4):49-54. doi: 10.4103/00195359.110896

23. Musani A, Khan FA, Malik S, Khambaty Y. Fine needle aspiration cytology-sensitivity and specificity in thyroid lesions. J Ayub Med Coll Abbottabad. 2011;23(1):34-36. 